This article was downloaded by: [Research Center of Eco-Environmental Sciences]

On: 18 March 2015, At: 19:59

Publisher: Taylor \& Francis

Informa Ltd Registered in England and Wales Registered Number: 1072954 Registered office: Mortimer House, 37-41 Mortimer Street, London W1T 3J H, UK

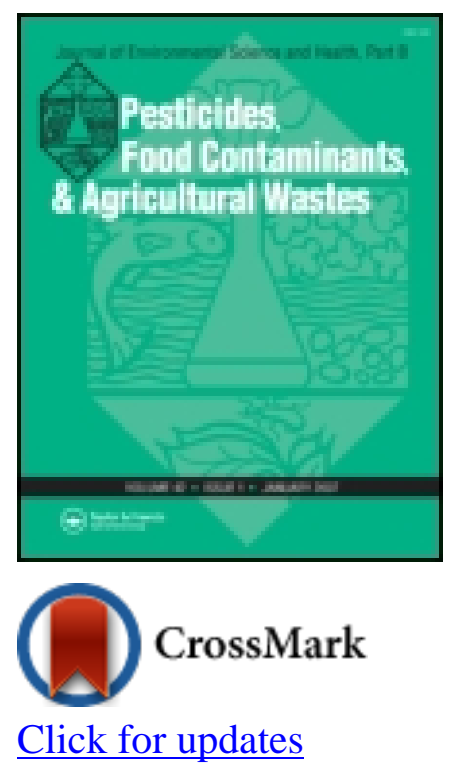

J ournal of Environmental Science and Health, Part B:
Pesticides, Food Contaminants, and Agricultural Wastes

Publication details, including instructions for authors and subscription information:

http:// www.tandfonline.com/loi/lesb20

\title{
Environmental behavior of benalaxyl and furalaxyl enantiomers in agricultural soils
}

\author{
Fang Qin ${ }^{\mathrm{ab}}$, Yong X. Gao ${ }^{\mathrm{a}}$, Bao Y. Guo ${ }^{\mathrm{a}}$, Peng Xu ${ }^{\mathrm{a}}$, Jian Z. Li ${ }^{\mathrm{a}} \&$ Hui L. Wang ${ }^{\mathrm{a}}$ \\ ${ }^{a}$ Research Center for Eco-Environmental Sciences, Chinese Academy of Sciences, Beijing, \\ China \\ ${ }^{b}$ Department of Environmental Engineering, North China Institute of Science and \\ Technology, Yanjiao, Beijing, China \\ Published online: 28 J ul 2014.
}

To cite this article: Fang Qin, Yong X. Gao, Bao Y. Guo, Peng Xu, Jian Z. Li \& Hui L. Wang (2014) Environmental behavior of benalaxyl and furalaxyl enantiomers in agricultural soils, J ournal of Environmental Science and Health, Part B: Pesticides, Food Contaminants, and Agricultural Wastes, 49:10, 738-746, DOI: 10.1080/03601234.2014.929482

To link to this article: http:// dx. doi.org/ 10.1080/03601234.2014.929482

\section{PLEASE SCROLL DOWN FOR ARTICLE}

Taylor \& Francis makes every effort to ensure the accuracy of all the information (the "Content") contained in the publications on our platform. However, Taylor \& Francis, our agents, and our licensors make no representations or warranties whatsoever as to the accuracy, completeness, or suitability for any purpose of the Content. Any opinions and views expressed in this publication are the opinions and views of the authors, and are not the views of or endorsed by Taylor \& Francis. The accuracy of the Content should not be relied upon and should be independently verified with primary sources of information. Taylor and Francis shall not be liable for any losses, actions, claims, proceedings, demands, costs, expenses, damages, and other liabilities whatsoever or howsoever caused arising directly or indirectly in connection with, in relation to or arising out of the use of the Content.

This article may be used for research, teaching, and private study purposes. Any substantial or systematic reproduction, redistribution, reselling, loan, sub-licensing, systematic supply, or distribution in any form to anyone is expressly forbidden. Terms \& Conditions of access and use can be found at http:// www.tandfonline.com/page/terms-and-conditions 


\title{
Environmental behavior of benalaxyl and furalaxyl enantiomers in agricultural soils
}

\author{
FANG QIN ${ }^{1,2}$, YONG X. GAO ${ }^{1}$, BAO Y. GUO ${ }^{1}$, PENG XU ${ }^{1}$, JIAN Z. LI ${ }^{1}$ and HUI L. WANG ${ }^{1}$ \\ ${ }^{1}$ Research Center for Eco-Environmental Sciences, Chinese Academy of Sciences, Beijing, China \\ ${ }^{2}$ Department of Environmental Engineering, North China Institute of Science and Technology, Yanjiao, Beijing, China
}

\begin{abstract}
The enantioselective environmental behavior of the chiral fungicides benalaxy and furalaxyl in agricultural soils in China was studied. Although sorption onto soils was non-enantioselective, the leaching of benalaxy and furalaxyl was enantioselective in soil columns. The concentrations of the $S$-enantiomers of both fungicides in the leachates were higher than the $R$-enantiomers. This can be attributed to enantioselective degradation of the two fungicides in the soil column. Enantioselective degradation of the two fungicides was verified by soil dissipation experiments, and the $R$-enantiomers degraded faster than the $S$-enantiomers in partial soils. The half-life was 27.7-57.8 days for $S$-benalaxyl, 20.4-53.3 days for $R$-benalaxyl, 19.3-49.5 days for $S$-furalaxyl and 11.434.7 days for $R$-furalaxyl. The degradation process of the two fungicide enantiomers followed the first-order kinetics $\left(R^{2}>0.96\right)$. Compared to furalaxyl, benalaxyl degraded more slowly and degradation was less enantioselective. These results are attributed to the influence of soil physicochemical properties, soil microorganisms, and environmental factors.
\end{abstract}

Keywords: Chiral fungicides, enantioselective environmental behavior, benalaxyl, furalaxyl.

\section{Introduction}

Benalaxyl (methyl $N$-(2, 6-dimethylphenyl)- $N$-(phenylacetyl)- $D L$-alaninate, CAS number 71626-11-4) and furalaxyl (methyl $\mathrm{N}$-(2, 6-dimethylphenyl)- $N$-(2-furanylcarbonyl)$D L$ - alaninate, CAS number 57646-30-7) (Fig. 1), are two types of chiral systemic acylanilide fungicides that are widely used for disease control and plant protection caused by Phytophthora sp., Pythium sp. and other Oomycetes. ${ }^{[1,2]}$ The two fungicides can be absorbed by the roots, stalks and leaves, and move to all parts of the plant to protect against downy mildews, late blight, damping off, and root, stem and fruit rots. ${ }^{[3,4]}$ Although the fungicidal activity of benalaxyl and furalaxyl are mainly attributed to their $R$ enantiomer, ${ }^{[5,6]}$ both of them are presently marketed in racemic formulations. Previous studies ${ }^{[7-9]}$ have shown that, for chiral pesticides, enantiomers may differ in their activity, toxicity and environmental fate. In these situations, it is necessary to evaluate the behavior of chiral pesticide enantiomers in organisms and the environment, which is beneficial for reducing potential environmental

Address correspondence to Hui Li Wang, Research Center for Eco-Environmental Sciences, Chinese Academy of Sciences, Shuangqing Road 18, Haidian District, Beijing 100085, China; E-mail: huiliwang@rcees.ac.cn

Received February 17, 2014. damage from racemic mixtures, and for promoting scientific and rational application of pesticides for the environmental safety and public health. ${ }^{[10-12]}$

During pesticide application, only a small amount of applied pesticides display protective and eradicative action to fight against plant diseases ${ }^{[13]}$ whereas a large amounts of pesticides reach the soil and result in widespread soil contamination. ${ }^{[14,15]}$ Thus, it is important to study the soil environmental behavior of chiral pesticide enantiomers to reduce environmental and human health risks. Previous studies ${ }^{[16]}$ have demonstrated that enantioselective degradation of benalaxyl in certain soils is a microbiologically mediated process, and $R$-benalaxyl degrades more rapidly than $S$-benalaxyl in aerobic soils. Enantioselective degradation of benalaxyl was often influenced by $\mathrm{pH}$, and the greatest enantioselectivity was found in soils with the highest $\mathrm{pH}$ value. ${ }^{[16]}$ As far as we know, enantioselective degradation of furalaxyl in the environmental matrix has not been reported. Furthermore, until now there is no report about the sorption and leaching processes of benalaxyl and furalaxyl enantiomers in soils. The enantioselective processes of sorption, leaching and degradation could affect the fate of chiral pesticides in the environment. ${ }^{[17]}$

The objectives of the study are listed as follows: (i) to investigate the enantioselective sorption of benalaxyl and furalaxyl in six Chinese agricultural soils with varying physicochemical properties, (ii) to determine the leaching process of the two fungicides through soil columns and 

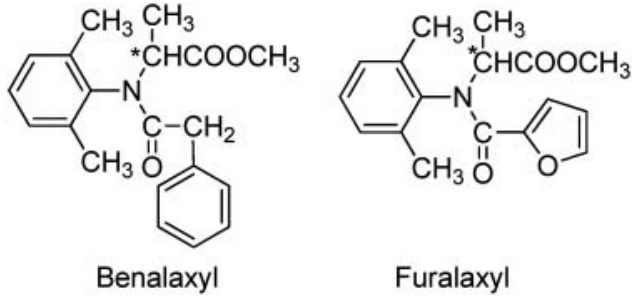

Furalaxyl

Fig. 1. Chemical structures of benalaxyl and furalaxyl. * Asymmetric carbon atom.

(iii) to determine the enantioselective dissipation of the two fungicides in these soils.

\section{Materials and methods}

\section{Chemicals and soils}

Rac-benalaxy (chemical purity $>98 \%$ ) and rac-furalaxyl (chemical purity $>98 \%$ ) and their enantiomers (enantiomeric purity $>97 \%$ ) were prepared via reported methods. ${ }^{[18-20]}$ The synthetic procedure was the same as synthesis of benalaxyl enantiomers we have discussed in detail. ${ }^{[18]}$ Acetonitrile (HPLC grade) was obtained from Fisher Scientific (Fair Lawn, NJ, USA). The water was purified with a Milli-Q system. Silica-based sorbents $\left(\mathrm{C}_{18}\right)$ and primary secondary amine (PSA, Si- $\left(\mathrm{CH}_{2}\right)_{3}-\mathrm{NH}-$ $\left.\left(\mathrm{CH}_{2}\right)_{2}-\mathrm{NH}_{2}\right)$ were obtained from Agela Technologies (Tianjin, China). All other chemicals and solvents were of analytical grade and commercially available.

The test soils were selected from different agriculture regions of China that had not been treated with benalaxyl and furalaxyl in the last 5 years. All topsoil samples $(0$ $20 \mathrm{~cm}$ ) were collected after removing vegetation. The soils were sieved $(2 \mathrm{~mm})$ and air-dried at room temperature and stored in a dark, dry place until a few days before they were used. The physicochemical properties of the soils are measured by China Agricultural University and shown in Table 1.

\section{Sorption experiment}

Sorption experiments with different soils were conducted by the batch equilibration procedure similar to that described by Celis et al. ${ }^{[12]}$ Sorption measurements were conducted in triplicate. Initial aqueous fungicide racemate solutions contained $0.1 \%$ acetonitrile concentration $\left(1.0 \mathrm{mg} \mathrm{L}^{-1}\right)$, which is representative of the 1 to $2 \mathrm{~kg} \mathrm{ha}^{-1}$ fungicide concentration field applied. The air-dried soils $(4.0 \mathrm{~g})$ were added to an aqueous solution of each fungicide $(8.0 \mathrm{~mL})$ in $20 \mathrm{~mL}$ glass centrifuge tubes. The tubes were covered with aluminum foil to reduce light exposure. The suspensions were equilibrated by shaking on a reciprocating platform shaker at 120 cycle $\min ^{-1}$ at $20 \pm 2^{\circ} \mathrm{C}$ for $24 \mathrm{~h}$ and were then centrifuged at 5,000 rpm for $15 \mathrm{~min}$. After centrifugation, the aqueous supernatant was separated. Then, a $2.0 \mathrm{~mL}$ aqueous solution was filtered through a $0.22 \mu \mathrm{m}$ filter, and analyzed by chiral high-performance liquid chromatography-tandem mass spectrometry (HPLC-MS/MS). The initial fungicide solution in tubes without soil also underwent the above procedures and analyses as a control sample. No loss of the two fungicides was observed during the sorption experiment. In our study, the amount of each enantiomer adsorbed in the soil, $\mathrm{C}_{\mathrm{s}}\left(\mathrm{mg} \mathrm{kg}^{-1}\right)$, was calculated according to Eq. (1).

$$
C_{s}=\left(C_{\mathrm{ini}}-C_{e}\right) \times 8 / 4
$$

where $C_{\text {ini }}$ is $0.5 \mathrm{mg} \mathrm{L}^{-1}$, which is the initial solution concentration of each enantiomer. $\mathrm{C}_{\mathrm{e}}\left(\mathrm{mg} \mathrm{L}^{-1}\right)$ is the equilibrium solution concentration of each enantiomer. Sorption distribution coefficients $\left(\mathrm{K}_{\mathrm{d}}, \mathrm{L} \mathrm{kg}^{-1}\right)$ were calculated using Eq. (2).

$$
K_{d}=C_{s} / C_{e}
$$

The enantiomer fraction (EF) in the equilibrated solutions during the sorption experiments was calculated according to Harner et al. ${ }^{[21]}$ as:

$$
\mathrm{EF}=C_{\mathrm{e}-\mathrm{S}} /\left(C_{\mathrm{e}-\mathrm{S}}+C_{\mathrm{e}-\mathrm{R}}\right)
$$

where $C_{\mathrm{e}-\mathrm{S}}$ and $C_{\mathrm{e}-\mathrm{R}}$ are the equilibrium solution concentrations of the $S$ - and $R$-enantiomers of benalaxyl or furalaxyl, respectively.

Table 1. Physicochemical characteristics of the soils used.

\begin{tabular}{llccccccc}
\hline Soil & Soil site $^{\mathrm{a}}$ & Sand $(\%)$ & Silt $(\%)$ & Clay $(\%)$ & Soil texture & $p H^{\mathrm{b}}$ & $C_{\text {org }}(\%)$ & CEC $_{\left(\mathrm{cmol} \mathrm{kg}^{-1}\right)}$ \\
\hline Soil 1 & Heilongjiang & 51 & 38 & 11 & Loam & 6.03 & 2.77 & 14.20 \\
Soil 2 & Henan & 68 & 13 & 19 & Sand loam & 8.19 & 1.38 & 5.63 \\
Soil 3 & Shandong & 56 & 27 & 17 & Sand loam & 7.79 & 2.08 & 6.17 \\
Soil 4 & Jiangsu & 24 & 30 & 47 & Clay & 8.15 & 1.95 & 8.64 \\
Soil 5 & Sichuan & 21 & 32 & 47 & Clay & 6.32 & 2.72 & 11.80 \\
Soil 6 & Guangxi & 59 & 21 & 19 & Sand loam & 5.51 & 0.71 & 3.10 \\
\hline
\end{tabular}

${ }^{a}$ The provinces in China.

${ }^{b}$ Suspension of soil in water, 1:2.5 (w/w). 


\section{Column leaching experiment}

Leaching was studied in glass columns $(3.1 \times 30 \mathrm{~cm}$ i.d. $)$ with a sand plate filled with air-dried soil, following a procedure similar to that described by Gámiz et al. ${ }^{[22]}$ All leaching experiments were conducted in triplicate. The columns with a sand plate were packed with $160 \mathrm{~g}(20 \mathrm{~cm})$ of soil (Soils 1, 3 and 4), and $10 \mathrm{~g}$ of sea sand was placed on the soil surface. Before the application of benalaxyl or furalaxyl, deionized water was added to the columns and allowed to drain for $24 \mathrm{~h}$. The pore volumes $\left(\mathrm{V}_{\mathrm{p}}\right)$ for each soil column were calculated from the difference between the amount of water added and the amount of water recovered in leachates. The pore volume $\left(\mathrm{V}_{\mathrm{p}}\right)$ of the columns after saturation was $64 \pm 2 \mathrm{~mL}$ for soil $1,56 \pm 2 \mathrm{~mL}$ for soil 3 and $52 \pm 2 \mathrm{~mL}$ for soil 4 . Rac-benalaxy or rac-furalaxyl $(0.15 \mathrm{mg})$ was dissolved in $3 \mathrm{~mL}$ of water (contained $0.1 \%$ acetonitrile) and applied to the top of the soil columns. Twenty-four hours after benalaxyl or furalaxyl application, columns were leached daily using distilled water $(15 \mathrm{~mL})$. The columns were covered with aluminum foil to reduce light exposure. The leachates were collected daily, filtered and analyzed by HPLC-MS/MS to determine the concentration of $S$ - and $R$-enantiomers of the two fungicides. At the end, soils in the columns were extracted with acetonitrile to determine the residual amount of fungicide.

The predicted retardation factor $(\mathrm{RF})$ represented the expected maximum concentration of chemical $\left(C_{\max }\right)$ peaks position in leachates. ${ }^{[23]}$ The RF value was compared with the measured $C_{\max }$ peaks position of the two fungicides enantiomers in the leaching, and was calculated according to the following equation: ${ }^{[24]}$

$$
\mathrm{RF}=1+(\rho / \theta) K_{d}
$$

where $\rho$ is the bulk density of the soil column $\left(\mathrm{g} \mathrm{cm}^{-3}\right), \theta$ is the soil column volumetric water content $\left(\mathrm{cm}^{3} \mathrm{~cm}^{-3}\right)$, and $K_{\mathrm{d}}\left(\mathrm{L} \mathrm{kg}^{-1}\right)$ is the sorption distribution coefficient for $S$ and $R$-enantiomers.

\section{Dissipation experiment}

Three replicates, consisting of air-dried soil (200 g), were spiked homogeneously with rac-benalaxyl or rac-furalaxyl at a concentration of $2 \mathrm{mg} \mathrm{kg}^{-1}$ soil, and then incubated in glass jars at $20 \pm 2{ }^{\circ} \mathrm{C}$ for 60 days. The procedure (dilution spike) was shown as follows: benalaxyl or furalaxyl $(0.4 \mathrm{mg})$ was dissolved in acetone $(10 \mathrm{~mL})$, and then, the acetone solution was slowly added to dry soil $(50 \mathrm{~g})$. The spiked soil was placed in a fume hood overnight to remove acetone. After the acetone evaporated, the contaminated dry soil $(50 \mathrm{~g})$ was mixed thoroughly with $150 \mathrm{~g}$ of uncontaminated medium. The final concentration of rac-benalaxyl or rac-furalaxyl was $2 \mathrm{mg} \mathrm{kg}^{-1}$ soil. Water was added to each soil to maintain a constant moisture content. The water content was close to those during column leaching experiment (see above), i.e., $40 \%$ for soil 1 , $35 \%$ for soil 3 and $33 \%$ for soil 4 on a weight basis. The loss of water by evaporation was compensated through the addition of distilled water each week. The soil samples (3.0 g per sample) were taken out and extracted with acetonitrile $(8.0 \mathrm{~mL})$. The mixture was vortex-mixed for $1 \mathrm{~min}$ and exposed to ultrasonic vibration for $20 \mathrm{~min}$. After being cleaned by PSA and $\mathrm{C}_{18}$, the extractions were analyzed by HPLC-MS/MS. At each sampling time, the enantiomer fraction (EF) was calculated using Eq. (5). Benalaxyl and furalaxyl enantiomers dissipation curves were fitted to the first-order kinetics equation (Eq. (6)) and half-lives $\left(t_{1 / 2}\right)$ were calculated using Eq. (7).

$$
\begin{aligned}
\mathrm{EF} & =\mathrm{C}_{\mathrm{S}} /\left(\mathrm{C}_{\mathrm{S}}+\mathrm{C}_{\mathrm{R}}\right) \\
\mathrm{C} & =\mathrm{C}_{0} \mathrm{e}^{-k t} \\
t_{1 / 2} & =0.6931 / k
\end{aligned}
$$

\section{Enantioselective analysis of benalaxy and furalaxyl}

HPLC-MS/MS analyses were performed by using a Thermo Fisher Scientific (Waltham, MA, USA) instrument equipped with an Accela 600 pump, an Accela autosampler, and a Quantum Access triple quadrupole mass spectrometer (TSQ Quantum Access MAX, Waltham, Massachusetts, USA) equipped with a heated electrospray ionization (HESI) source. Benalaxyl and furalaxyl enantiomers were separated on a Chiralpak IC column $(4.6 \times$ $250 \mathrm{~mm}$ i.d., Daicel, Shanghai, China) with a $5 \mu \mathrm{m}$ particle size. The mobile phase was a mixture of $55 \%$ acetonitrile and $45 \%$ water with a flow rate of $0.35 \mathrm{~mL} \mathrm{~min}{ }^{-1}$. Chromatographic separation was conducted at $20^{\circ} \mathrm{C}$, and the injection volume was $10 \mu \mathrm{L}$. The mass spectrometer and HESI source were used in positive-ion mode with selected reaction monitoring (SRM) mode to determine the concentrations of benalaxyl and furalaxyl. The parameters for the MS detector were as follows: spray voltage, $3200 \mathrm{~V}$; sheath gas pressure, $40 \mathrm{Arb}$; auxiliary gas pressure, $5 \mathrm{Arb}$; collision gas (Ar): $1.5 \mathrm{mTorr}$; vaporizer temperature, $250^{\circ} \mathrm{C}$; and capillary temperature, $350^{\circ} \mathrm{C}$. For benalaxyl, transition $m / z 326>148$ was used for quantification, $\mathrm{m} / z 326>207$ was used for confirmation, and collision energies were $20 \mathrm{eV}$ and $16 \mathrm{eV}$, respectively. For furalaxyl, transition $\mathrm{m} / z 302>242$ was used for quantification, $m / z 302>95$ was used for confirmation, and collision energies were $15 \mathrm{eV}$ and $29 \mathrm{eV}$, respectively.

Stock solutions $\left(1,000 \mathrm{mg} \mathrm{L}^{-1}\right)$ of rac-benalaxyl and $r a c$-furalaxyl in acetonitrile were prepared, respectively. A series of standard working solutions at 1, 5, 10, 50, 100, 500 and $1,000 \mathrm{ng} \mathrm{mL}^{-1}$ concentrations were prepared from stock solution by serial dilution with acetonitrile. According to the procedure described above, a series of 
matrix-matched standard solutions with the same concentrations were also prepared by adding blank soil sample extracts (acetonitrile extracts for dissipation experiments and water extracts for sorption and leaching experiments) to each serially diluted standard solution. The calibration curves were generated by regression analysis of the peak area of quantification ion transition against analyte concentrations. Blank soil sample analysis was performed to check interference from the matrix. Matrix-induced signal suppression/enhancement (SSE) was determined by comparing the slope of matrix-matched standard curve with the slope of the standard calibration curve.

Recovery of benalaxyl and furalaxyl enantiomers were determined in blank soil samples that were fortified at different levels $\left(0.01,0.1\right.$ and $1.0 \mathrm{mg} \mathrm{kg}^{-1}$ based on five replicates). The blank soil samples that were added to water to maintain a constant moisture content were prepared the same way as the samples that were used in the dissipation experiment. The spiked blank samples were left for $1 \mathrm{~h}$ to ensure that the spiked pesticides were evenly distributed and then extracted, determined, and analyzed as previously described. Recoveries were calculated by comparing the measured concentration to the fortified concentrations, and the relative standard deviation (RSD) revealed the method precision. The stability of benalaxyl and furalaxyl enantiomers was evaluated in stock solutions and matrix extracts under known soil $\mathrm{pH}$ values (Table 1). The stock solutions and matrices extracts of the enantiomers, which were prepared 2 months previously and stored at $-20{ }^{\circ} \mathrm{C}$, were evaluated by comparison of newly prepared working solutions. The stability of the two fungicides enantiomers in soil samples beneath the current $\mathrm{pH}$ values was also determined when comparing newly prepared, spiked soil samples with the soil samples which was prepared 2 months previously and stored at $-20^{\circ} \mathrm{C}$.

\section{Results and discussion}

\section{Assay validation}

Good linear calibration curves were obtained over a $1-$ $1,000 \mathrm{ng} \mathrm{mL} \mathrm{m}^{-1}$ range for each enantiomer of benalaxyl and furalaxyl. There was no significant matrix effect and enantiomerization for the two fungicide enantiomers with HPLC-MS/MS method. Benalaxyl and furalaxyl enantiomers were baseline separated. There were no endogenous interference peaks at the same retention times as the enantiomers. The retention times for $S$-furalaxyl, $R$-furalaxyl, $R$-benalaxyl and $S$-benalaxyl were $23.67,28.48$, 30.49 and $36.25 \mathrm{~min}$, respectively. The matrix effect was calculated by comparing the slope of matrix-matched standard curve with the slope of the standard calibration curve, and the slope ratios were in the range of 0.872 to 0.983 . Thus, there was no significant matrix-induced ion signal suppression/enhancement (SSE).
The recoveries for benalaxyl and furalaxyl enantiomers at levels between 0.01 and $1.0 \mathrm{mg} \mathrm{kg}^{-1}$ were ranged between 85 and $99 \%$ in the soil with an RSD below $12 \%(n$ $=5$ for each sample type). The limit of detection (LOD) and quantification (LOQ) for the two fungicides enantiomers were defined as the concentrations that gave a signalto-noise ratio of 3 and 10 . The LOQ was estimated to be $1.33 \mu \mathrm{g} \mathrm{kg}^{-1}$ (for benalaxyl) and $0.65 \mu \mathrm{g} \mathrm{kg}^{-1}$ (for furalaxyl). The LOD was estimated to be 0.40 and $0.20 \mu \mathrm{g}$ $\mathrm{kg}^{-1}$ for benalaxyl and furalaxyl, respectively. Compared with newly prepared solutions, the stability test of the two fungicides enantiomers was also evaluated in stock solutions and matrixes under the same soil $\mathrm{pH}$ values which were prepared 2 months previously and stored at $-20^{\circ} \mathrm{C}$. Benalaxyl and furalaxyl enantiomers were stable under the stock solutions and the spiked soil samples under the current $\mathrm{pH}$ at $-20^{\circ} \mathrm{C}$.

\section{Sorption experiment}

The distribution coefficients $\left(\mathrm{K}_{\mathrm{d}}\right)$ and enantiomer fractions (EFs) measured for the $S$ - and $R$-enantiomers of benalaxyl and furalaxyl sorption for soil samples are shown in Figure 2. The $K_{\mathrm{d}}$ values for the $S$ - and $R$-enantiomers of benalaxyl resulted in no significant difference, as for the $K_{\mathrm{d}}$ values for furalaxyl enantiomers. After $24 \mathrm{~h}$-equilibration, the EF values of benalaxyl and furalaxyl enantiomers remained $0.50 \pm 0.02$. Results indicated that the sorption of benalaxyl and furalaxyl by the soils was non-enantioselective. These were similar to previous non-enantioselective sorption studies of rac-metalaxyl on different properties of soils. ${ }^{[12,25-27]}$ The $K_{\mathrm{d}}$ values also indicate that benalaxyl was adsorbed in more amounts compared with furalaxyl under similar experimental conditions (Fig. 2).

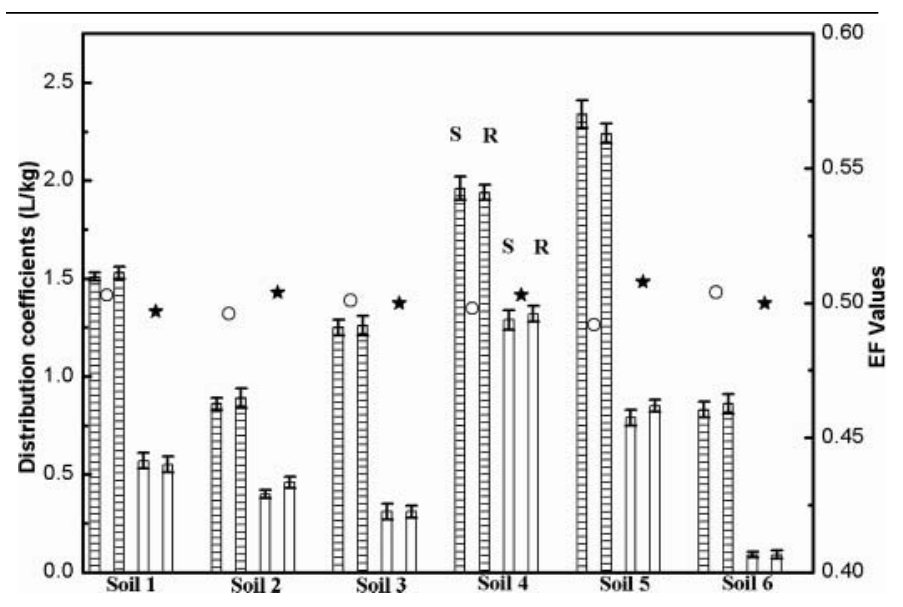

Fig. 2. Distribution coefficients $\left(K_{\mathrm{d}}\right)$ for $S$ - and $R$-enantiomers sorption in soils and enantiomer fractions (EFs) in the equilibrated solutions. $(\boxminus)$ for benalaxyl and $(\square)$ for furalaxyl, $(\bigcirc)$ for benalaxyl EF value and $(\star)$ for furalaxyl EF value. Error bars are the standard deviations of the means of sorption tests on three replicates. 
Table 2. Summary of column leaching data extracted from the relative and cumulative breakthrough curves (BTCs).

\begin{tabular}{|c|c|c|c|c|c|}
\hline Soil & Compound & $\mathrm{C}_{\max }\left(m g L^{-1}\right)$ & Position of $\mathrm{C}_{\max }\left(\times \mathrm{V}_{p}\right)$ & $R F$ & Total leached (\%) \\
\hline \multirow[t]{2}{*}{ Soil 1} & $S$-benalaxyl & $0.50 \pm 0.04$ & 5.4 & 4.8 & $79 \pm 8$ \\
\hline & $R$-benalaxyl & $0.47 \pm 0.03$ & 5.4 & 4.8 & $72 \pm 7$ \\
\hline \multirow[t]{2}{*}{ Soil 3} & $S$-benalaxyl & $0.45 \pm 0.04$ & 5.0 & 4.6 & $65 \pm 7$ \\
\hline & $R$-benalaxyl & $0.38 \pm 0.03$ & 5.0 & 4.6 & $52 \pm 6$ \\
\hline \multirow[t]{2}{*}{ Soil 4} & $S$-benalaxyl & $0.35 \pm 0.03$ & 8.6 & 7.0 & $46 \pm 7$ \\
\hline & $R$-benalaxyl & $0.25 \pm 0.04$ & 8.6 & 7.0 & $36 \pm 6$ \\
\hline \multirow[t]{2}{*}{ Soil 1} & $S$-furalaxyl & $0.59 \pm 0.05$ & 2.3 & 2.4 & $91 \pm 8$ \\
\hline & $R$-furalaxyl & $0.56 \pm 0.04$ & 2.3 & 2.4 & $81 \pm 9$ \\
\hline \multirow[t]{2}{*}{ Soil 3} & $S$-furalaxyl & $0.73 \pm 0.04$ & 2.4 & 1.9 & $87 \pm 7$ \\
\hline & $R$-furalaxyl & $0.55 \pm 0.04$ & 2.4 & 1.9 & $64 \pm 7$ \\
\hline \multirow[t]{2}{*}{ Soil 4} & $S$-furalaxyl & $0.44 \pm 0.04$ & 4.0 & 5.0 & $73 \pm 9$ \\
\hline & $R$-furalaxyl & $0.34 \pm 0.03$ & 4.0 & 5.0 & $52 \pm 8$ \\
\hline
\end{tabular}

$\pm:$ Standard deviations.

This can be attributed to the facts that benalaxyl has a lower solubility rate in water and a larger octanol-water partition coefficient, which is correlated with the adsorption of organic compounds on soil organic matter (SOM). ${ }^{[28,29]}$ Adsorption of the two fungicides in the soils followed almost the same trend as the SOM content changing, which was supported by the $K_{\mathrm{d}}$ values (benalaxyl Soils $5>4>1>3>2 \approx 6$, furalaxyl Soils $4>5>1>2$ $>3>6$ ).

Previous studies indicate that the SOM and other soil components such as soil clay play an essential role in the sorption process of non-ionic organic compounds. ${ }^{[26,29-32]}$ The sorption of the two fungicides by Soils 1, 3, 4 and 5 were considerably greater than that of the other soils, most likely as a result of their greater organic matter and clay contents (Table 1). The mineralogy of the clay fraction in the soils also affects the sorption of organic compounds which preferentially adsorbed on mineral surfaces. The clay mineralogy in the soils was $66 \%$ illite, $12 \%$ montmorillonite and $22 \%$ kaolinite for Soil $3,{ }^{[33]} 38 \%$ illite, 53\% montmorillonite and 9\% kaolinite for Soil $5,{ }^{[34]} 65 \%$ illite, $10 \%$ montmorillonite and $25 \%$ kaolinite for Soil $6 .{ }^{[35]}$ The results of sorption experiment (Fig. 2) also corroborated the important role of the mineral surfaces in benalaxyl and furalaxyl sorption. At $\mathrm{pH}>5$, the fraction of hydrophobic pesticides benalaxyl and furalaxyl adsorbed by the SOM was not $\mathrm{pH}$ dependent. The results were consistent with those reported by Gondar et al. ${ }^{[29]}$ for the non-ionic fungicides metalaxyl and penconazole in soils containing different amounts of organic carbon. Gondar et al. found that for $\mathrm{pH}>5$, the adsorption of non-ionic pesticides did not vary with $\mathrm{pH}$, while at lower $\mathrm{pH}$ values, the fraction adsorbed on the solid phase increased as the $\mathrm{pH}$ decreased. For both benalaxyl and furalaxyl in the six Chinese soil samples selected for this study, the amounts of the two fungicides adsorbed did not vary as the capacity of exchange cations increased. This result suggested that the electrostatic effect was not as important as the hydrophobic effect for facilitating or retarding the sorption of non-ionic pesticides such as benalaxyl and furalaxyl.

\section{Leaching experiment}

Soils 1, 3 and 4 were selected for leaching experiments because they have similar organic carbon contents, but different clay textures, and their responses to benalaxyl and furalaxyl sorption were different (Table 1 and Fig. 2). The breakthrough curves (BTCs) and EF values for $S$ - and $R$ enantiomers of benalaxyl and furalaxyl in the leachates collected are shown in Table 2 and Figure 3. The maximum concentration of benalaxyl enantiomers appeared in leachates at 5.4, 5.0 and 8.6 times the pore volume $\left(\mathrm{V}_{\mathrm{p}}\right)$ in soil columns 1, 3 and 4, respectively. The position of the maximum concentration of furalaxyl enantiomers in Soils 1, 3 and 4 appeared at lower pore volumes 2.3, 2.4 and 4.0 times, respectively. Benalaxyl enantiomers leached in soil columns were all slightly later than predicted RF values, which were calculated from Equation 4.

The breakthrough curves (BTCs) showed that the two fungicide enantiomers were retarded in the soil columns since the concentration peaks were above one pore volume. Fungicide enantiomers appeared earlier in Soils 1 and 3, but later in Soil 4, which had more clay content. The higher clay content in Soil 4 induced later and more flat BTCs, lower maximum peaks and higher pore volumes (Table 2 and Fig. 3), indicating higher sorption. These results indicated that leaching processes were related to sorption. In addition to soil texture, the physicochemical properties of organic compounds also affected the sorption and leaching of pesticides. ${ }^{[36]}$ In all selected soils, the sorption capacity of benalaxyl was higher than that of furalaxyl (Fig. 2), and the high sorption capacity of benalaxyl in soils increased its residence time in the soil columns. This may be one reason that benalaxyl enantiomers leached later than furalaxyl enantiomers in Soils 1,3 and 4 . 

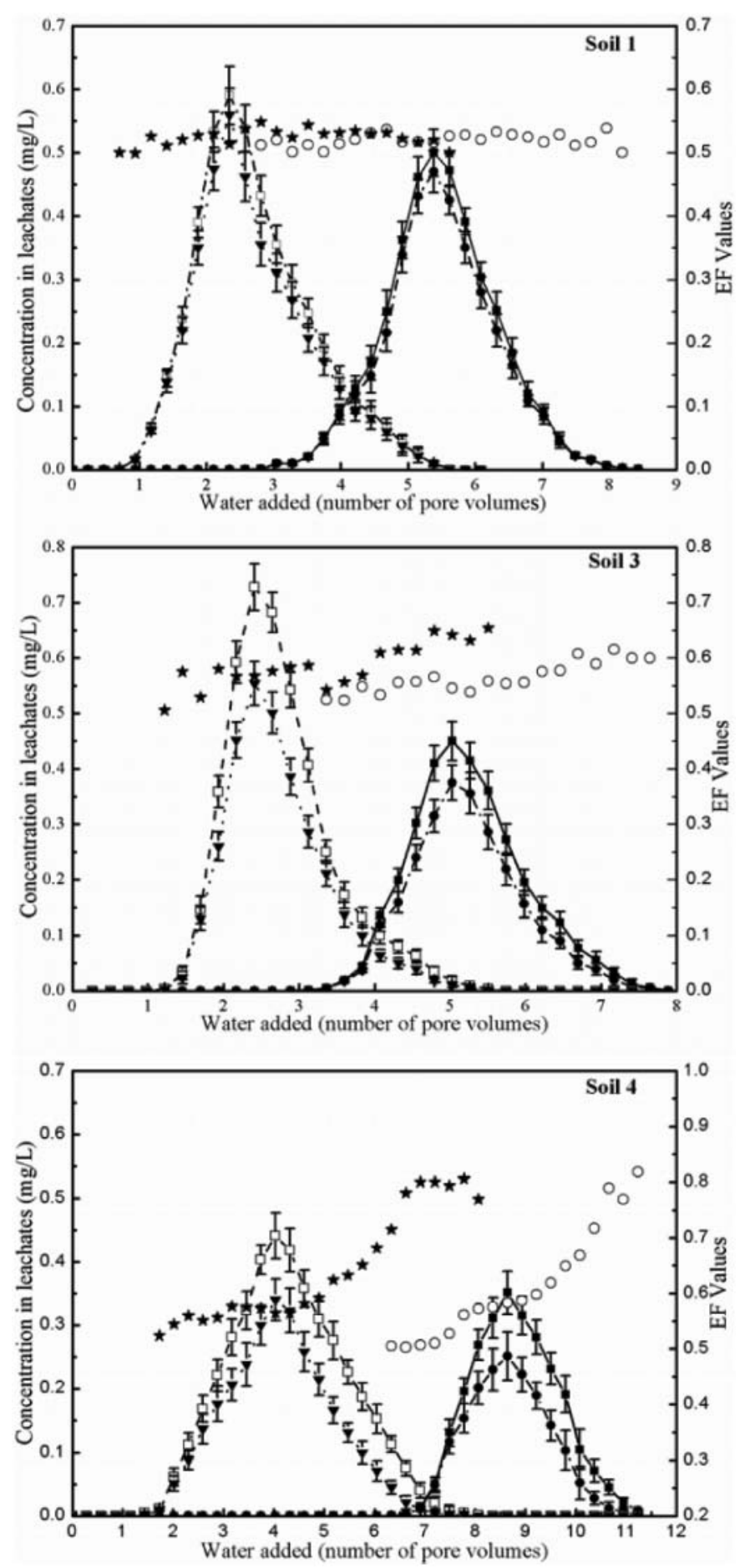

Fig. 3. Relative and cumulative breakthrough curves (BTCs) and enantiomer fractions (EF) for benalaxyl and furalaxyl enantiomers

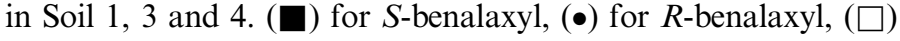
for $S$-furalaxyl, $(\boldsymbol{\nabla})$ for $R$-furalaxyl, $(\bigcirc)$ for benalaxyl EF value and $(\star)$ for furalaxyl EF value. Error bars are the standard deviations of the means of column leaching tests on three replicates.

From Figure 3 and Table 2, it was observed that benalaxyl enantiomers had similar retardation during the column leaching experiment. This was also observed for furalaxyl enantiomers. The enantiomer concentrations of benalaxyl or furalaxyl in leachates from Soil 1 were almost the same and the EF values were approximately 0.5 . Most of the two enantiomers for each fungicide were recovered in leachates from Soil 1 during the whole leaching processes, which lasted 25-40 days. The loss of benalaxyl (21$28 \%$ ) and furalaxyl (9-19\%) in the leachate from Soil 1 may be attributed to the degradation in the soil column. The result revealed that benalaxyl and furalaxyl degradation behavior was non-enantioselective in Soil 1. The concentrations of $S$-enantiomer of benalaxyl and furalaxyl in leachates from Soils 3 and 4 were higher than $R$-enantiomer and the EF values exceeded 0.5, whereas the two fungicides leached from Soil 3 and 4 leached a relatively small amount. The total amount of furalaxyl leached from each soil column was more than benalaxyl. As the sorption process of benalaxyl and furalaxyl on soils was non-enantioselective, enantioselective leaching behavior in Soils 3 and 4 should be attributed to its enantioselective degradation behavior during leaching. The BTCs of Soils 3 and 4 were consistent with the diagram reported by Celis et al. ${ }^{[12]}$ based on the non-enantioselective sorption and enantioselective degradation for the chiral compound metalaxyl. The enantioselectivity during leaching resulted from degradation behavior, which could be proven using the dissipation experiment below, so it was important to evaluate chiral pesticides dissipation in the soil environment.

\section{Dissipation experiment}

The dissipation of benalaxyl in Soils 2, 3 and 4 was enantioselective, and the degradation of $R$-enantiomer was faster than for the $S$-enantiomer (Fig. 4). The EF values exceeded 0.50 after 20 days and increased with time. These deviations were statistically significant $(P<0.05)$. The dissipation of $S$ - and $R$-benalaxyl enantiomers in soils was described by single first-order kinetics (Eq. 6) with determination coefficients $R^{2}=0.97-0.99$ (Table 3 and Fig. 4). The half-lives of $S$-benalaxyl and $R$-benalaxyl were $27.7-$ 57.8 days and 20.4-53.3 days, respectively (Table 3). However, the dissipation of benalaxyl enantiomers was non-enantioselective in other soils. One possible reason is that the amounts and activities of microorganism varied in different soil types since microbial decomposition was identified as the most important factor in enantioselective metabolism of many chiral chemicals in soils. ${ }^{[4-7,14,37]}$

The dissipation of furalaxyl enantiomers was not significantly different in Soil 1 (Fig. 4), as supported by the inference of the leaching experiment. The fualaxyl dissipation in other soils selected for this study was enantioselective, with the $R$-enantiomer being degraded faster than the $S$ enantiomer (Fig. 4), leading to residues with a composition $[S]>[R]$. The EF values deviated from 0.5 , and reached $0.62-0.79$ at the end of the dissipation experiment. The dissipation of $S$ - and $R$-furalaxyl enantiomers in soils fit well with the single first-order kinetics curve (Eq. 6) with determination coefficients $R^{2}=0.96-0.99$ (Table 3 

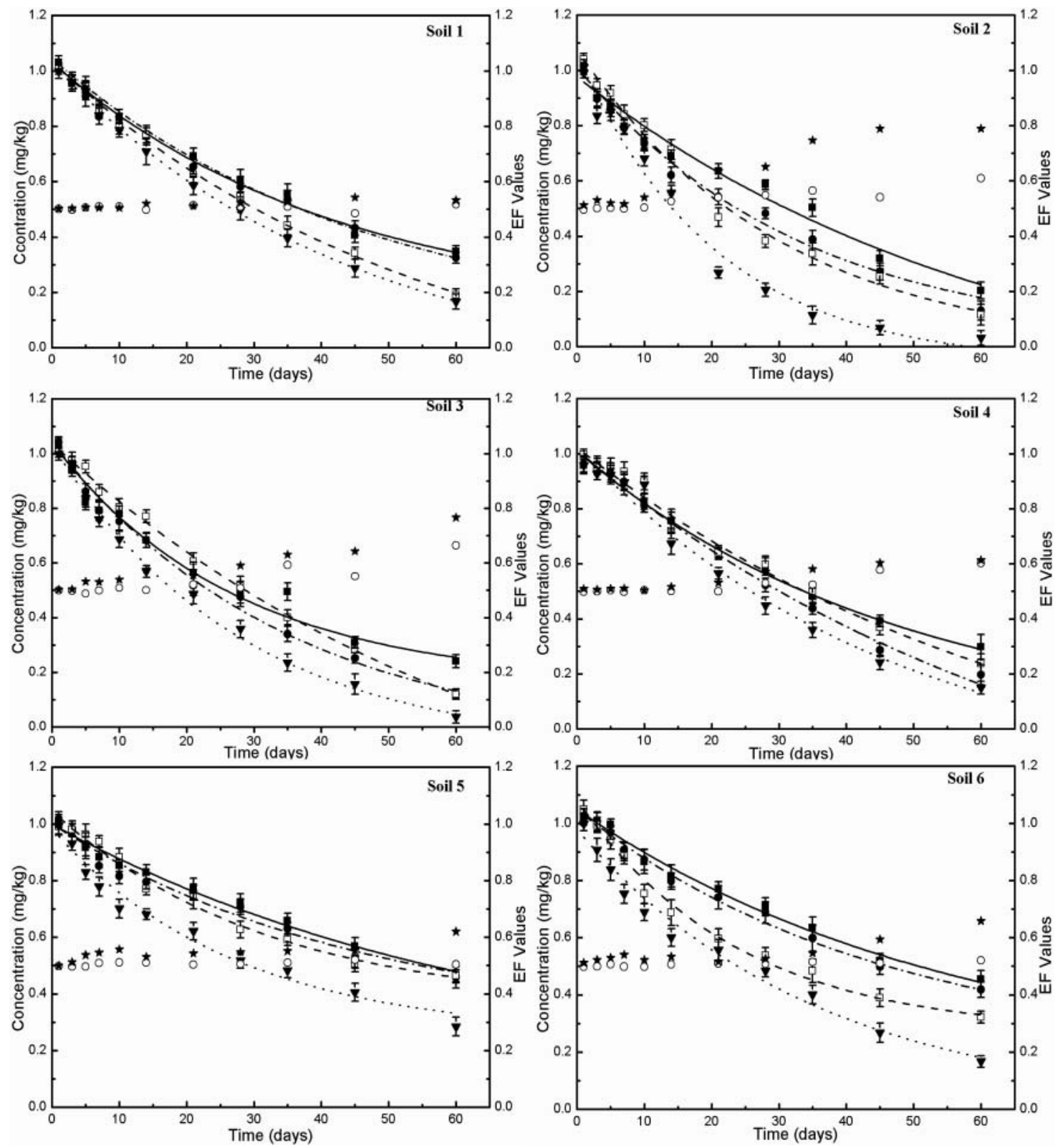

Fig. 4. The dissipation curves and enantiomer fractions (EF) with time during the dissipation experiment of benalaxyl and furalaxyl

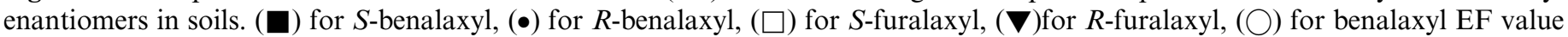
and $(\star)$ for furalaxyl EF value. Error bars are the standard deviations of the means of dissipation tests on three replicates.

and Fig. 4), and the half-lives of $S$-furalaxyl and $R$-furalaxyl were 19.3-49.5 days and 11.4-34.7 days, respectively (Table 3). Compared with benalaxyl, furalaxyl enantiomers dissipated at a relatively faster degradation rate. This can be attributed to the fact that the dissipation of organic compounds in soils was affected by sorption processes, which are correlated with the physicochemical properties of chemicals. Sorption made organic chemicals unavailable to soil microorganisms and protected pesticides from degradation. ${ }^{[2,38]}$ Sorption also reduced the enantioselectivity of chiral pesticides degradation processes and made pesticides remain racemic longer than the readily biodegradable fraction. ${ }^{[12,39,40]}$
The dissipation of benalaxyl and furalaxyl enantiomers was faster in Soils 2 and 3 than in the other natural soils (Table 3 and Fig. 4). The lowest persistence of the two fungicides in Soils 2 and 3 can be attributed to the lower sorption distribution coefficients $\left(K_{\mathrm{d}}\right)$ (Fig. 2), which was produced by low soil organic matter (SOM) and clay content in Soils 2 and 3. Benalaxyl or furalaxyl in Soils 5 and 6 dissipated at a similar rate $\left(\mathrm{t}_{1 / 2}\right)$, but different sorption distribution coefficients $\left(K_{\mathrm{d}}\right)$ (Fig. 2$)$ were caused by a different soil composition parameters, such as SOM and clay content (Table 1). These results indicated that soil physicochemical and microbial characteristics might affect the degradation of the two fungicides in the environment. 
Table 3. Single first-order dissipation constants for benalaxyl and furalaxyl in soils.

\begin{tabular}{|c|c|c|c|c|c|c|c|c|}
\hline Test materials & Enantiomers & $\mathrm{k}^{\mathrm{a}}\left(d^{-1}\right)$ & $\mathrm{t}_{1 / 2}(d)$ & $\mathrm{R}^{2}$ & Enantiomers & $\mathrm{k}\left(d^{-1}\right)$ & $\mathrm{t}_{1 / 2}(d)$ & $\mathrm{R}^{2}$ \\
\hline \multirow[t]{2}{*}{ Soil 1} & $S$-benalaxyl & 0.018 & 38.5 & 0.98 & $S$-furalaxyl & 0.027 & 25.7 & 0.99 \\
\hline & $R$-benalaxyl & 0.019 & 36.5 & 0.99 & $R$-furalaxyl & 0.030 & 23.1 & 0.99 \\
\hline \multirow[t]{2}{*}{ Soil 2} & $S$-benalaxyl & 0.025 & 27.7 & 0.97 & $S$-furalaxyl & 0.036 & 19.3 & 0.99 \\
\hline & $R$-benalaxyl & 0.032 & 21.7 & 0.98 & $R$-furalaxyl & 0.061 & 11.4 & 0.99 \\
\hline \multirow[t]{2}{*}{ Soil 3} & $S$-benalaxyl & 0.024 & 28.9 & 0.98 & $S$-furalaxyl & 0.034 & 20.4 & 0.97 \\
\hline & $R$-benalaxyl & 0.034 & 20.4 & 0.99 & $R$-furalaxyl & 0.051 & 13.6 & 0.96 \\
\hline \multirow[t]{2}{*}{ Soil 4} & $S$-benalaxyl & 0.022 & 31.5 & 0.99 & $S$-furalaxyl & 0.024 & 28.9 & 0.98 \\
\hline & $R$-benalaxyl & 0.026 & 26.7 & 0.99 & $R$-furalaxyl & 0.033 & 21.0 & 0.99 \\
\hline \multirow[t]{2}{*}{ Soil 5} & $S$-benalaxyl & 0.012 & 57.8 & 0.99 & $S$-furalaxyl & 0.014 & 49.5 & 0.97 \\
\hline & $R$-benalaxyl & 0.013 & 53.3 & 0.97 & $R$-furalaxyl & 0.020 & 34.7 & 0.98 \\
\hline \multirow[t]{2}{*}{ Soil 6} & $S$-benalaxyl & 0.014 & 49.5 & 0.99 & $S$-furalaxyl & 0.019 & 36.5 & 0.97 \\
\hline & $R$-benalaxyl & 0.015 & 46.2 & 0.99 & $R$-furalaxyl & 0.028 & 24.8 & 0.98 \\
\hline
\end{tabular}

${ }^{a} k$ : Elimination rate coefficient.

$R^{2}$ : Determination coefficient.

According to Table 3 and Figure 4, the dissipation of benalaxyl and furalaxyl might be influenced by $\mathrm{pH}$ value. Faster dissipation and higher enantioselectivity were found in Soils 2, 3 and 4, which had higher $\mathrm{pH}$ values of 8.19, 7.79 and 8.15 , respectively, whereas slower dissipation and less enantioselectivity were observed in Soils 1, 5 and 6, which had a lower $\mathrm{pH}$ values of $6.03,6.32$ and 5.51, respectively. These results were consistent with those obtained by Wang et al. ${ }^{[16]}$ for benalaxyl in several agricultural soils, indicating that in the soil with higher $\mathrm{pH}$ value of 8.6, $R$-enantiomer of benalaxyl was degraded faster than $S$-enantiomer.

The dissipation rate for individual enantiomers of the two fungicides was also investigated in this study and the result showed that benalaxyl and furalaxyl were configurationally stable in soils during 60 day periods, showing no conversion of $R$ - to $S$-enantiomers, and vice-versa. Residues of the main metabolites, benalaxyl acid or furalaxyl acid, were lower in soils. Sorption protected the two fungicides from degradation and reduced the enantioselective degradation process. Benalaxyl and furalaxyl enantioselective degradation might affect their retention and leaching behavior in soil columns. The loss amounts in the leachate due to the enantioselective degradation in soil columns induced fungicides enantioselective leaching behavior. The physicochemical properties of the soils and amounts and activities of microorganisms could have played an important role, taking part in the sorption, leaching and degradation of the pesticide.

\section{Conclusions}

In this study, the sorption, leaching and dissipation of benalaxyl and furalaxyl enantiomers were assayed in Chinese agricultural soils. Sorption of the two fungicides was non-enantioselective and affected by SOM and soil texture, and the high clay content and SOM induced strong sorption. However, the leaching of the two fungicides was enantioselective in the topsoil layer. The results were attributed to the enantioselective degradation of the enantiomers. This was verified by the dissipation experiment. Benalaxyl and furalaxyl in partial soils displayed enantioselective dissipation, and the degradation of $R$-enantiomer in soils was faster than degradation of the $S$-enantiomer. Dissipation processes were depended on sorption capacity in soils because sorption may protect chiral pesticides from biodegradation. The physicochemical properties of chiral pesticides could also affect their behavior in the environment. The sorption, leaching and degradation of benalaxyl were different from furalaxyl in soils. In order to maximize the efficacy and reduce the environmental impact of chiral pesticides, we advise that the $R$-enantiomers of both benalaxyl and furalaxyl, which have higher fungicidal activity and faster degradation rates than the $S$ enantiomers, replaced $r a c$-benalaxyl and $r a c$-furalaxyl for environmental safety and public health.

\section{Funding}

This work was supported by the National High Technology Research and Development Program (863) of China (No. 2012AA06A302) and National Natural Science Foundation of China (Nos. 21277163 and 41301569).

\section{References}

[1] Davidse, L.C.; Gerritsma, O.C.M.; Ideler, J.; Pie, K.; Velthuis, G. C.M. Antifungal modes of action of metalaxyl, cyprofuram, benalaxyl and oxadixyl in phenylamide-sensitive and phenylamide-resistant strains of Phytophthora megasperma f. sp. medicaginis and Phytophthora infestans. Crop Prot. 1988, 7(6), 347-355.

[2] Zhang, H.; Wang, X.Q.; Jin, L.X.; Qian, M.R.; Wang, X.Y.; Xu, H.; Qi, P.P.; Wang, Q.; Wang, M.H. Enantioselective determination of acylamino acid fungicides in vegetables and fruits by chiral liquid chromatography coupled with tandem mass spectrometry. J. Sep. Sci. 2012, 35(15), 1869-1876.

[3] Houseworth, L.D. Excerpts from the new products and services from industry. Plant Dis. 1987, 71(3), 286. 
[4] Sulimma, L.; Bullach, A.; Kusari, S.; Lamshöft, M.; Zühlke, S.; Spiteller, M. Enantioselective degradation of the chiral fungicides metalaxyl and furalaxyl by Brevibacillus brevis. Chirality. 2013, 25 (6), 336-340.

[5] Buerge, I.J.; Poiger, T.; Müller, M.D.; Buser, H.R. Enantioselective degradation of metalaxyl in soils: chiral preference changes with soil pH. Environ. Sci. Technol. 2003, 37(12), 2668-2674.

[6] Chen, S.W.; Liu, W.P. Enantioselective degradation of metalaxyl in anaerobic activated sewage sludge. Bull. Environ. Contam. Toxicol. 2009, 82(3), 327-331.

[7] Hegeman, W.J.M.; Laane, R.W.P.M. Enantiomeric enrichment of chiral pesticides in the environment. Rev. Environ. Contam. Toxicol. 2002, 173(1), 85-116.

[8] Zadra, C.; Marucchini, C.; Zazzerini, A. Behavior of metalaxyl and its pure $R$-enantiomers in sunflower plants (Helianthus annuus). J. Agric. Food Chem. 2002, 50(19), 5373-5377.

[9] Wang, Q.X.; Qiu, J.; Zhu, W.T.; Jia, G.F.; Li, J.L.; Bi, C.L.; Zhou, Z.Q. Stereoselectivity degradation kinetics of theta-cypermethrin in rats. Environ. Sci. Technol. 2006, 40(3), 721-726.

[10] Magrans, J.O.; Alonso-Prados, J.L.; García-Baudín, J.M. Importance of considering pesticide stereoisomerism-proposal of a scheme to apply Directive 91/414/EEC framework to pesticide active substances manufactured as Isomeric mixtures. Chemosphere. 2002, 49(5), 461-469.

[11] Ye, J.; Zhao, M.R.; Liu, J.; Liu, W.P. Enantioselectivity in environmental risk assessment of modern chiral pesticides. Environ. Pollut. 2010, 158(7), 2371-2383.

[12] Celis, R.; Gámiz, B.; Adelino, M.A.; Hermosín, M.C.; Cornejo, J. Environmental behavior of the enantiomers of the chiral fungicide metalaxyl in Mediterranean agricultural soils. Sci. Total Environ. 2013, 444(1), 288-297.

[13] Pimentel, D. Amounts of pesticides reaching target pests: environmental impacts and ethics. J. Agric. Environ. Ethic. 1995, 8(1), 1729.

[14] United States Environmental Protection Agency (US EPA). Carbofuran; Final Tolerance Revocations. 40 CFR part 180. Rules Regul. 2009, 74(93), 23045-23095. Available at http://www.epa. gov/fedrgstr/EPA-PEST/2009/May/Day-15/p11396.htm (accessed May 2009).

[15] Bermúdez-Couso, A.; Nóvoa-Muñoz, J.C.; Arias-Estévez, M.; Fernández-Calviño, D. Influence of different abiotic and biotic factors on the metalaxyl and carbofuran dissipation. Chemosphere. 2013, 90(10), 2526-2533.

[16] Wang, X.Q.; Jia, G.F.; Qiu, J.; Diao, J.L.; Zhu, W.T.; Lv, C.G.; Zhou, Z.Q. Stereoselective degradation of fungicide benalaxyl in soils and cucumber plants. Chirality. 2007, 19(4), 300-306.

[17] Garrison, A.W. Probing the enantioselectivity of chiral pesticides. Environ. Sci. Technol. 2006, 40(1), 16-23.

[18] Gao, Y.X.; Chen, J.H.; Wang, H.L.; Liu, C.; Lv, X.T.; Li, J.Z.; Guo, B.Y. Enantiomerization and enantioselective bioaccumulation of benalaxyl in Tenebrio molitor larvae from wheat bran. J. Agric. Food Chem. 2013, 61(38), 9045-9051.

[19] Effenberger, F.; Burkard, U.; Willfahrt, J. Enantioselektive synthese $N$-substituierter $\alpha$-Aminocarbonsäuren aus $\alpha$-Hydroxycarbonsäuren. Liebigs. Ann. Chem. 1986, 1986(2), 314-333.

[20] Palla, O.; Mirenna, L.; Colombo, L.; Zini, G.; Filippini, L.; Zanardi, G. Fungicidal compositions based on (N-phenylacetyl-N2, 6-xylyl) methyl alaninate. US Patent 6228885 B1, May 8, 2001.

[21] Harner, T.; Wiberg, K.; Norstrom, R. Enantiomer fractions are preferred to enantiomer ratios for describing chiral signatures in environmental analysis. Environ. Sci. Technol. 2000, 34(1), 218220.

[22] Gámiz, B.; Celis, R.; Hermosin, M.C.; Cornejo, J. Organoclays as soil amendments to increase the efficacy and reduce the environmental impact of the herbicide fluometuron in agricultural soils. J. Agric. Food Chem. 2010, 58(13), 7893-7901.
[23] Flores-Céspedes, F.; González-Pradas, E.; Fernández-Pérez, M.; Villafranca-Sánchez, M.; Socías-Viciana, M.; Ureña-Amate, M.D. Effects of dissolved organic carbon on sorption and mobility of imidacloprid in soil. J. Environ. Qual. 2002, 31(3), 880-888.

[24] Rao, P.S.C.; Hornsby, A.G.; Jessup, R.E. Indices for ranking the potential for pesticide contamination of groundwater. Soil Crop Sci. Soc. Fla. Proc. 1985, 44(1), 1-8.

[25] Bermúdez-Couso, A.; Fernández-Calviño, D.; Pateiro-Moure, M.; Garrido-Rodríguez, B.; Nóvoa-Muñoz, J.C.; Arias-Estévez, M. Adsorption and desorption behavior of metalaxyl in intensively cultivated acid soils. J. Agric. Food Chem. 2011, 59(13), 72867293.

[26] Fernandes, M.C.; Cox, L.; Hermosín, M.C.; Cornejo, J. Adsorption-desorption of metalaxyl as affecting dissipation and leaching in soils: role of mineral and organic components. Pest. Manag. Sci. 2003, 59(5), 545-552.

[27] Marín-Benito, J.M.; Sánchez-Martín, M.J.; Andrades, M.S.; Pérez-Clavijo, M.; Rodríguez-Cruz, M.S. Effect of spent mushroom substrate amendment of vineyard soils on the behavior of fungicides: 1. Adsorption-desorption of penconazole and metalaxyl by soils and subsoils. J. Agric. Food. Chem. 2009, 57(20), 9634 9642.

[28] Komárek, M.; Čadková, E.; Chrastný, V.; Bordas, F.; Bollinger, J. C. Contamination of vineyard soils with fungicides: a review of environmental and toxicological aspects. Environ. Int. 2010, 36(1), $138-151$.

[29] Gondar, D.; López, R.; Antelo, J.; Fiol, S.; Arce, F. Effect of organic matter and $\mathrm{pH}$ on the adsorption of metalaxyl and penconazole by soils. J. Hazard. Mater. 2013, 260, 627-633.

[30] Monkiedje, A.; Spiteller, M.; Bester, K. Degradation of racemic and enantiopure metalaxyl in tropical and temperate soils. Environ. Sci. Technol. 2003, 37(4), 707-712.

[31] Romero, E.; Matallo, M.B.; Peña, A.; Sánchez-Rasero, F.; Schmitt-Kopplin, Ph.; Dios, G. Dissipation of racemic mecoprop and dichlorprop and their pure $R$-enantiomers in three calcareous soils with and without peat addition. Environ. Pollut. 2001, 111(2), 209-215.

[32] Celis, R.; Koskinen, W.C. An isotopic exchange method for the characterization of the irreversibility of pesticide sorption-desorption in soil. J. Agric. Food Chem. 1999, 47(2), 782-790.

[33] Sun, Z.J.; Ma, L.; Zhang, M.; Chen, B.C.; Song, F. P. Composition of clay minerals and adsorption characteristics of main orchard soil s in Shandong. J. Soil Water Conserv. 2007, 21(3), 5760 .

[34] Xu, S.; Xu G.L.; Sun C.M.; Sun Y. Mineralogical character of main clay soils in Chengdu. Bull. Sci. Technol. 2012, 28(10), 7-10.

[35] Pang, C.Y.; Lai, L.R. The Characteristics of the mineral and chemical compositions of the red clay of Guilin city. Miner. Resour. Geol. 2001, 15(6), 734-737.

[36] Kah, M.; Brown, C.D. Adsorption of ionizable pesticides in soils. Rev. Environ. Contam. Toxicol. 2006, 188, 149-217.

[37] Lewis, D.L.; Garrison, A.W.; Wommack, K.E.; Whittemore, A.; Steudler, P.; Melillo, J. Influence of environmental changes on degradation of chiral pollutants in soils. Nature. 1999, 401, 898-901.

[38] Scow, K.M.; Alexander, M. Effect of diffusion on the kinetics of biodegradation: experimental results with synthetic aggregates. Soil Sci. Soc. Am. J. 1992, 56(1), 128-134.

[39] Ulrich, E.M.; Foreman, W.T.; Van Metre, P.C.; Wilson, J.T.; Rounds, S.A. Enantiomer fractions of chlordane components in sediment from U.S. Geological Survey sites in lakes and rivers. Sci. Total Environ. 2009, 407(22), 5884-5893.

[40] Wong, F.; Kurt-Karakus, P.; Bidleman, T.F. Fate of brominated flame retardants and organochlorine pesticides in urban soil: volatility and degradation. Environ. Sci. Technol. 2012, 46(5), 2668 2674. 